\title{
Horizontal and Vertical Turbulent Fluxes Forced by a Gravity Wave Event in the Nocturnal Atmospheric Surface Layer Over the Amazon Forest
}

\author{
Marcelo Zeri · Leonardo D. A. Sá
}

Received: 23 March 2010 / Accepted: 7 November 2010 / Published online: 25 November 2010

(C) Springer Science+Business Media B.V. 2010

\begin{abstract}
A nocturnal gravity wave was detected over a south-western Amazon forest during the Large-Scale Biosphere-Atmosphere experiment in Amazonia (LBA) in the course of the dry-to-wet season campaign on October 2002. The atmospheric surface layer was stably stratified and had low turbulence activity, based on friction velocity values. However, the passage of the wave, an event with a period of about 180-300 s, caused negative turbulent fluxes of carbon dioxide $\left(\mathrm{CO}_{2}\right)$ and positive sensible heat fluxes, as measured by the eddy-covariance system at $60 \mathrm{~m}(\approx 30 \mathrm{~m}$ above the tree tops). The evolution of vertical profiles of air temperature, specific humidity and wind speed during the wave movement revealed that cold and drier air occupied the sub-canopy space while high wind speeds were measured above the vegetation. The analysis of wind speed and scalars high frequency data was performed using the wavelet technique, which enables the decomposition of signals in several frequencies allowed by the data sampling conditions. The results showed that the time series of vertical velocity and air temperature were $-90^{\circ}$ out of phase during the passage of the wave, implying no direct vertical transport of heat. Similarly, the time series of vertical velocity and $\mathrm{CO}_{2}$ concentration were $90^{\circ}$ out of phase. The wave was not directly associated with vertical fluxes of this variable but the mixing induced by its passage resulted in significant exchanges in smaller scales as measured by the eddy-covariance system. The phase differences between horizontal velocity and both air temperature and $\mathrm{CO}_{2}$ concentration were, respectively, zero and $180^{\circ}$, implying phase and anti-phase relationships. As a result, the wave contributed to positive horizontal fluxes of heat and negative horizontal fluxes of carbon dioxide. Such results have to be considered in nocturnal boundary-layer surface-atmosphere exchange schemes for modelling purposes.
\end{abstract}

\footnotetext{
M. Zeri (ख)

Energy Biosciences Institute, University of Illinois at Urbana-Champaign, 1206, West Gregory Drive, Urbana, IL 61801, USA

e-mail: mzeri@illinois.edu
}

L. D. A. Sá

Centro Regional da Amazônia (CRA), Instituto Nacional de Pesquisas Espaciais (INPE), Parque da Ciência e Tecnologia do Guamá, Av. Perimetral, No. 2651, PA 66077-830, Belém, Brazil e-mail: leonardo.deane@pq.cnpq.br 
Keywords Amazon forest · Downbursts · Gravity waves · Nocturnal surface layer · Scalar fluxes · Wavelet analysis

\section{Introduction}

Atmospheric boundary-layer flow can be decomposed into three main components: the mean flow, the turbulence field and waves. Although they all exist in combination, turbulence accounts for most of the vertical surface-atmosphere scalar exchanges (Stull 1988). Atmospheric gravity waves exist because of a stable density stratification of the atmosphere. As important properties, we mention the capacity of such waves in transporting energy and momentum from one region of the atmosphere to another and the capability of generating turbulence during breaking processes (Meillier et al. 2008). Intermittent turbulence in the stable boundary layer (SBL) is often associated with breaking gravity waves and is among observed phenomena in the SBL that are responsible for intense vertical mixing at night (Chimonas 1985; Finnigan 1988; Lee et al. 1996, 1997). These wave phenomena are ubiquitous in the SBL and play an important role in exchange processes that are observed over forests (Lee et al. 1996, 1997). Both above and within canopy vegetation, such canopy waves present unique characteristics, such as short and monochromatic wave periods and low phase speed, as compared with waves that originate in the upper boundary layer (Lee 1997). Fitzjarrald and Moore (1990) reported motions that were associated with strong turbulent mixing and exchange of scalars such as carbon dioxide $\left(\mathrm{CO}_{2}\right)$ and water vapour during nights of stable stratification over the Amazon forest. In that study, cloudiness periods were associated with increased turbulent kinetic energy as a consequence of weakening of both radiative cooling and stable stratification intensity. The authors also observed oscillations in the canopy layer wind field that were related with an increase in wind speed above the forest and consequent higher wind stress at the forest-atmosphere interface. An increase in turbulent activity following perturbations in net radiation was also observed over a pine forest for the same latitude region by Cava et al. (2004).

The genesis of gravity waves over forests, also called canopy waves, has been attributed to shear instabilities near the canopy top, specifically Kelvin-Helmholtz instabilities (Lee 1997; Hu et al. 2002). The instabilities occur near the inflection point in the vertical profile of wind speed, generally located around the vegetation top (Garratt 1992). The wind shear at this height reduces the Richardson number below the critical value of 0.25 and triggers the instability (Lee et al. 1997; Lee 1997). Hu et al. (2002) proposed a four-stage life cycle for a canopy wave that is triggered near the tree tops, and also proposed that coherent structure phases, as sweeps and ejections, would be associated with one of the wave stages. Apart from forest-atmosphere interface, gravity waves in the SBL have been investigated in Antarctica (Rees et al. 2001) and over forest stands. The investigations of exchange processes in the SBL have experienced a remarkable progress with the SABLES (Stable Atmospheric Boundary Layer Experiment in Spain, as presented by Cuxart et al. (2000)), and CASES-99 (1999 Cooperative Atmosphere-Surface Exchange Study, presented in Blumen et al. (2001) and Poulos et al. (2002)) experiments.

Intermittent periods of turbulence as well as wave-like motions were detected during the CASES-99 experiment. Sun et al. (2002) used data from this experiment and described the turbulence intermittency caused by the passage of a cold air density current during the night of 18 October 1999. According to them, the fast-moving density current swept the surface and produced strong turbulent mixing above and below the canopy. Sun et al. (2004) analysed two wave-like motions that were detected during the same night and found that they were 
associated with thermal instability at the surface, when cold air was forced over warm air, and a downward transport of momentum. Wavelet methods are often used in such studies regarding gravity waves and turbulence interaction. Terradellas et al. (2005), using data from the CASES-99 experiment, separated contributions to the vertical flux of heat for different periods of oscillation. The events observed in the SBL produce a mixing of energy and scalars (e.g. temperature and carbon dioxide) and contribute to vertical and horizontal fluxes at time scales ranging from seconds to several minutes, as reported in Viana et al. (2009) for the SABLES2006 (Stable Atmospheric Boundary Layer Experiment in Spain 2006) experiment. Rees et al. (2001) reported the effects of two wave-like oscillations on the SBL over Antarctica: a small amplitude wave associated with the main flow and a large amplitude wave propogating $55^{\circ}$ from the main wind direction. The second wave was hypothesized to be associated with katabatic flows caused by local topography. In the current work, the effects of a wave event that occurred over an Amazon forest site in Brazil are characterised by analysing vertical profiles of scalars, as well as high frequency eddy-covariance data. Wavelet methods are used to decompose the signals at several temporal scales in order to determine the contribution of different frequencies to the vertical and horizontal fluxes of heat and $\mathrm{CO}_{2}$.

\section{Site and Data}

The measurements were carried out at the Jaru Biological Reserve, located about $100 \mathrm{~km}$ north of Ji-Paraná, in the Brazilian state of Rondônia. Kruijt et al. (2000) described this ecosystem as an open tropical rain forest, with a leaf area index of approximately $4 \mathrm{~m}^{2} \mathrm{~m}^{-2}$. The average tree height is $35 \mathrm{~m}$, but some branches reach up to $45 \mathrm{~m}$. The mean annual rainfall is $1,600 \mathrm{~mm}$ (Gash et al. 1996) and the average air temperature $(T)$ was $25.4^{\circ} \mathrm{C}$ for 2002. A 60-m tall micrometeorological tower was installed at approximately $600 \mathrm{~m}$ from the shore of Machado River (coordinates: $10^{\circ} 4^{\prime} 42.36^{\prime \prime} \mathrm{S} ; 61^{\circ} 56^{\prime} 1.62^{\prime \prime} \mathrm{W}$, at $145 \mathrm{~m}$ a.s.1.). The tower location can be seen in the satellite picture in Fig. 1. Illegal logging resulted in patches in the forest cover from the north-west to the north-east sectors. One of the "rules of thumb" in micrometeorology requires that the fetch extends to at least 100 times the height of measurement above the vegetation (Businger 1986; Garratt 1990). However, it has been reported that even moderate stable stratification can cause this area to be much larger (Leclerc and Thurtell 1990; Horst and Weil 1994). The eddy-covariance measurements during this experiment were performed at $\approx 30 \mathrm{~m}$ above the mean canopy height, requiring a fetch of at least $3 \mathrm{~km}$ (or more during nighttime). The deforested areas to the north and south-west certainly influenced the daytime and nighttime measurements, especially because the main wind directions at the site are north-north-east and south, according to the wind rose histogram in Fig. 2. The influence of these sectors on our results will be discussed in Sect. 4.1.

The data used in this work were obtained during the Dry-to-Wet LBA ${ }^{1}$ campaign that took place at several locations in the north-western Brazilian state of Rondônia from September to November 2002. This forest was the location of two previous campaigns of the LBA project and measurements were continuous until November 2002, when the tower was dismantled. A description of the energy balance components and turbulent fluxes for this site were reported in von Randow et al. (2004) and more recently in Zeri and Sá (2010), while the characteristics of the convective boundary layer for this region were presented in Fisch et al. (2004). Other

\footnotetext{
${ }^{1}$ Large-Scale Biosphere-Atmosphere Experiment in Amazonia, http://lba.cptec.inpe.br/lba.
} 


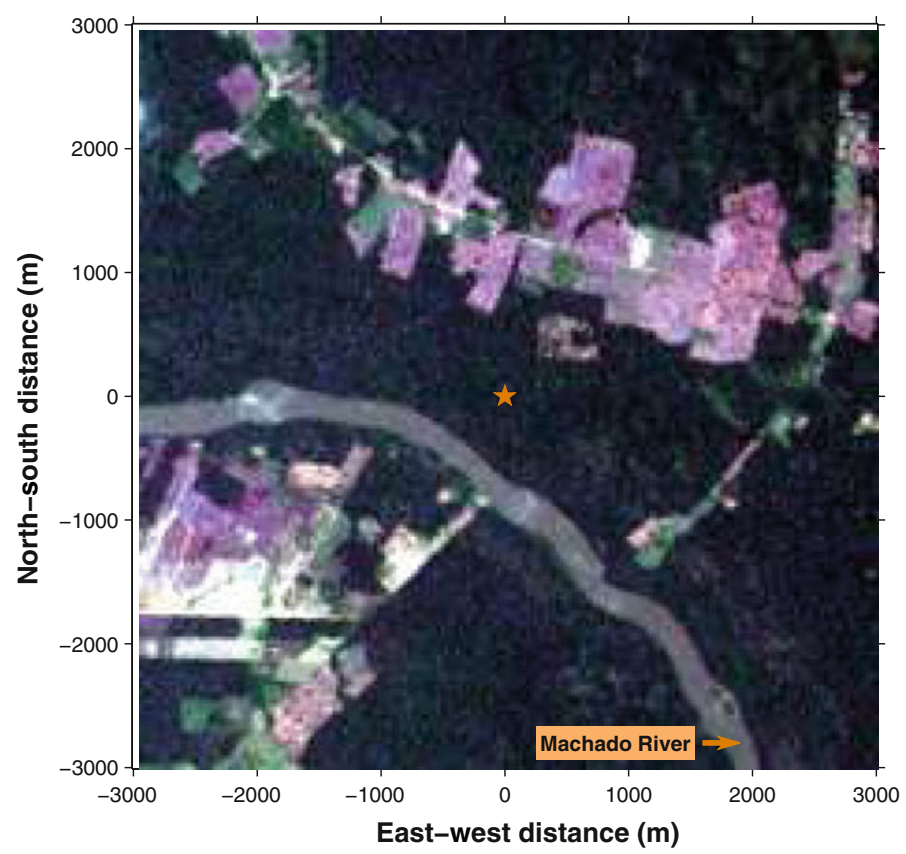

Fig. 1 Landsat 7 picture for 1 October 2002. Tower location is marked with the star

results and detailed site characteristics can be found in Kruijt et al. (2000), Andreae et al. (2002), Silva Dias et al. (2002) and von Randow et al. (2002).

For the 2002 intensive campaign, the tower was equipped with an eddy-covariance system installed at a height of $62.7 \mathrm{~m}$. The system consisted of a three-dimensional sonic anemometer (model Solent 1012R2, Gill Instruments, UK) and a closed path infra-red gas analyser (IRGA) model LICOR 6262 (LICOR Inc., Nebraska, USA), both operating at $10.4 \mathrm{~Hz}$. On 11 October 2002 an open path IRGA was added to the system, located close to the sonic anemometer. Air pressure was measured at a height of $40 \mathrm{~m}$ using a barometer model PTB100A, from Vaisala (Helsinki, Finland), and wind direction was assessed using a wind vane placed at $60 \mathrm{~m}$ height (model W200P, Vector Instruments, UK). Measurements of wind speed were made above and below the canopy using cup anemometers (model A100R, Vector Instruments, UK) placed at heights of 15, 25, 35, 37, 39, 41, 44, 50 and $60 \mathrm{~m}$. For air temperature and relative humidity, thermohygrometers (model HMP35A, Vaisala, Helsinki, Finland) were installed at the following heights: $3,12,22,28,33,37,42,52$ and $60 \mathrm{~m}$. The vertical profiles of wind speed, air temperature and relative humidity were averaged every minute. All the other variables were averaged every $30 \mathrm{~min}$.

\section{Methodology}

The Alteddy ${ }^{2}$ software was used to process the high frequency data and calculate the eddycovariance fluxes. The software was set up to apply a two-dimensional rotation to the coordinate system so that the horizontal wind components were aligned with the main flow and

2 http://www.climatexchange.nl/projects/alteddy/index.htm. 


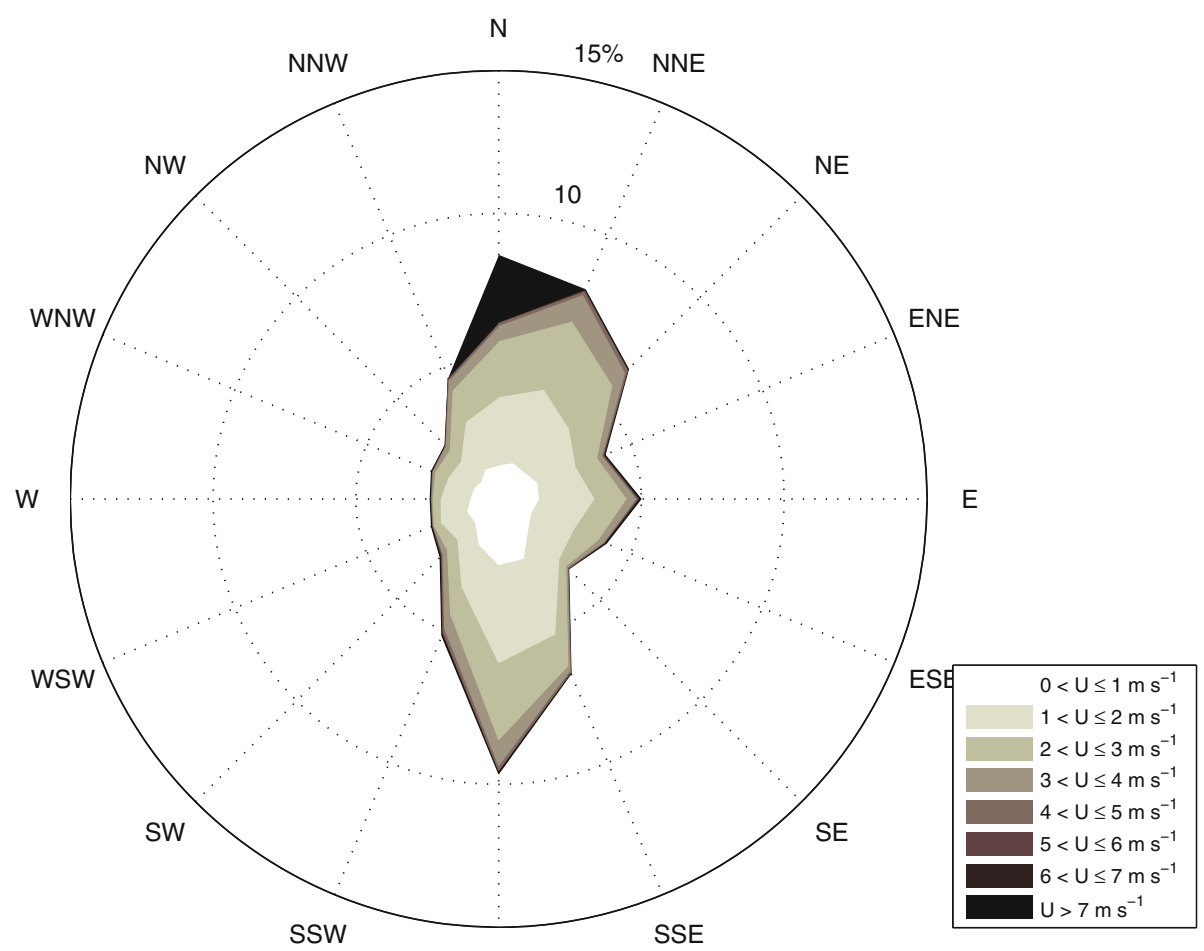

S

Fig. 2 Wind rose histogram for September-November 2002. Histogram calculated using bins of wind direction that were $22.5^{\circ}$ wide and centred around the cardinal marks (N, NNE, NE, etc.)

the average vertical velocity is forced to zero (Kaimal and Finnigan 1994). The Schotanus correction (Schotanus et al. 1983) was used to correct for the effects of humidity on the temperature measured by the sonic anemometer. The Webb correction (Webb et al. 1980) was applied to correct for the effects of air density on the measurements of the open path IRGA. The time lags introduced by the transport of air from the closed-path IRGA inlet to the analyser were determined and accounted for in each half-hour file before calculating the covariances. Finally, high frequency losses in the fluxes caused by both transport through the tubes and sensor separation were corrected according to Moore (1986). In addition, flags based on the quality control proposed by Foken et al. (2004) were generated for each flux every $30 \mathrm{~min}$.

\subsection{Wavelet Transform}

The continuous wavelet transform is a tool used to decompose a time series into its frequency components while keeping the information about their localisation in time (Daubechies 1992). It is generally used to analyse non-periodic features of geophysical signals (Farge 1992; Sá et al. 1998), specially characteristics of the turbulent flow and organised motions (coherent structures) observed in the time series of scalars over vegetated surfaces (Collineau and Brunet 1993a,b; Lu and Fitzjarrald 1994; Katul and Vidakovic 1998; von Randow et al. 2002; Thomas and Foken 2005; Bolzan and Vieira 2006). The wavelet decomposition is obtained 
by calculating the convolution between the discrete time series $x_{n}$ with scaled and translated versions of $\Psi$, a function called the wavelet mother. A wavelet mother can be continuous or discrete, must have zero mean and be localised both in time and in frequency. One example of such a function is the Morlet wavelet, defined as:

$$
\Psi(\eta)=\pi^{-1 / 4} e^{i \omega_{0} \eta} e^{-\eta^{2} / 2},
$$

where $\eta$ is the non-dimensional time parameter and $\omega_{0}$ is the non-dimensional frequency. Other kinds of wavelet functions and their characteristics can be found in Torrence and Compo (1998). The Morlet function was used in our study given its correct identification of spectral characteristics of known features of artificial time series on the turbulence production frequency range (Thomas and Foken 2005). After choosing the wavelet function, the wavelet transform is defined as:

$$
W(t, a)=\frac{1}{\sqrt{a}} \int_{-\infty}^{\infty} x(\tau) \Psi^{*}\left(\frac{\tau-t}{a}\right) \mathrm{d} \tau
$$

where $t$ is the time, $a$ is the scale parameter, $\tau$ is the integration variable that displaces the scaled versions of the wavelet mother along the time series $x_{n}$ and (*) denotes the complex conjugate. The wavelet technique can also be applied to a pair of time series $x$ and $y$ so that their common variability in frequency and time can be determined by the wavelet cross spectrum, calculated as $W_{x y}=W_{x} W_{y}^{*}$. The absolute value of $W_{x y}$ is the cross-wavelet power, proportional to the covariance between the two time series, and the complex part of $W_{x y}$ gives information about the phase difference between $x$ and $y$ (Grinsted et al. 2004). The results presented herein were corrected according to Liu et al. (2007), who demonstrated that the wavelet power spectrum should be divided by the scale coefficient so that it becomes physically consistent and unbiased.

\section{Results}

\subsection{Wave Event and Influence on the Turbulent Fluxes and Vertical Profiles of Scalars}

The wave event was observed on 21 October 2002 between 0400 and 0430 local time (0800 and 0830 UTC). The impact on the high frequency data of wind velocity, temperature and carbon dioxide (measured at $62.7 \mathrm{~m}$ ) can be seen in Fig. 3. The wave had a period of approximately $300 \mathrm{~s}$, lasted on the recorded data for 20-25 min, and had the strongest impact on the signals of vertical velocity $(w)$ and $\mathrm{CO}_{2}$ concentration $(c)$. The changes in $c$ between peaks and valleys of the wave were approximately $50 \mathrm{ppm}$, associated with peaks and valleys in vertical velocity. The valleys in $w$ preceded in some minutes strong decreases in $c$, while the peaks in $w$ caused strong increases in $c$. Although delayed in time, the relationship between these variables affected the vertical fluxes of carbon dioxide, which is further discussed in Sect. 4.2.

Rawinsonde data from a balloon released $5 \mathrm{~km}$ from the tower were analysed in order to study the surface-layer state during the wave passage (Fig. 4). The vertical profile of wind speed (panel a) reveals the presence of a moderate low-level jet (LLJ) at approximately 400 $\mathrm{m}$, denoted by the maximum velocity at this height. This result is in agreement with the observations of Prabha et al. (2008), who reported a relationship between moderate LLJs and enhanced turbulence activity at the surface as a consequence of the top-down induced mixing process above the LLJ height. The enhanced wind shear caused the wind direction 


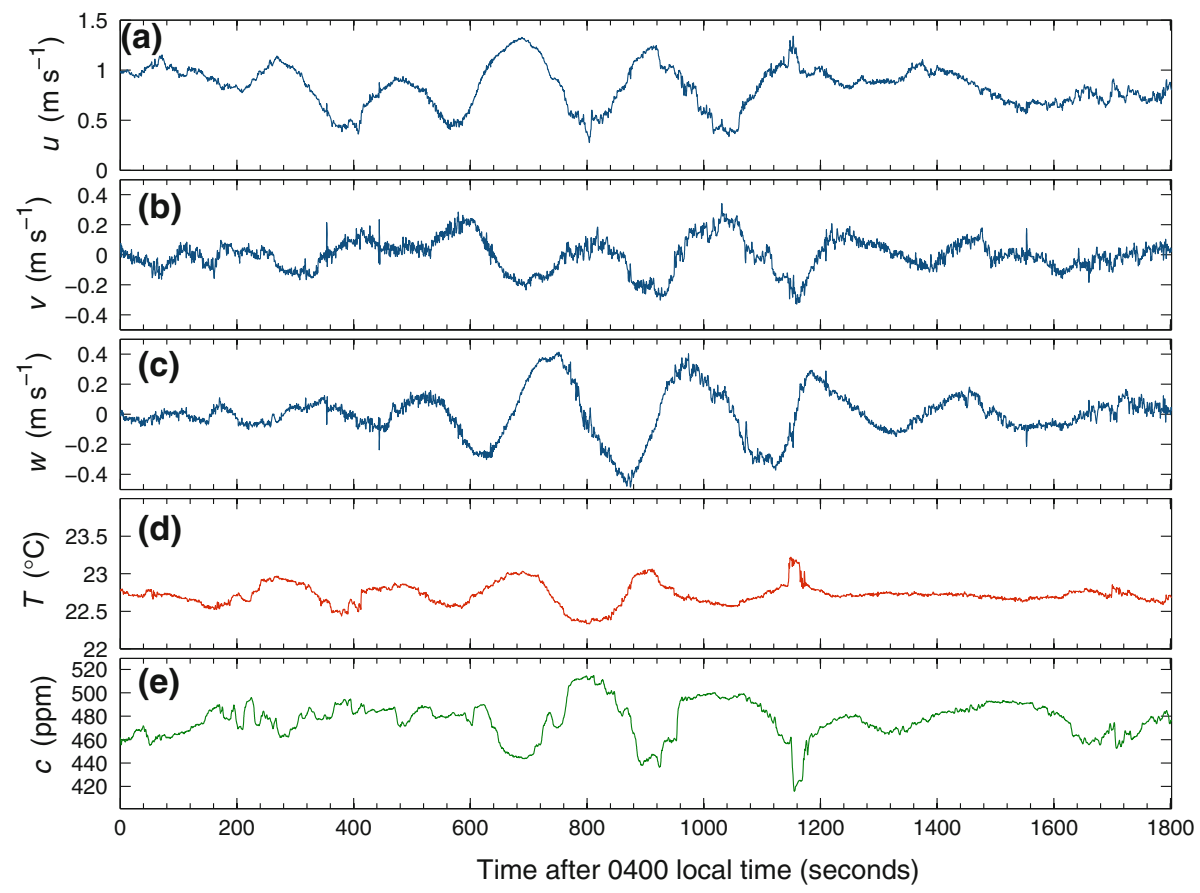

Fig. 3 Time series of the high frequency data during the wave event: a longitudinal wind velocity component, b transversal wind velocity component, $\mathbf{c}$ vertical wind velocity component, $\mathbf{d}$ air temperature, e $\mathrm{CO}_{2}$ concentration, $c$. Wind coordinate system rotated according to a two-dimensional scheme ( $u$ aligned with the main wind direction and $\bar{w}$ forced to zero). Frequencies below $\approx 1 \mathrm{~Hz}$ removed in order to eliminate spikes and for clarity in the plots. Frequencies corresponding to periods of $\approx 800 \mathrm{~s}$ or more were also removed, because $30 \mathrm{~min}$ of data would not be enough to record a significant number of events in that scale. All filtering done using the discrete wavelet transform

to steer to the north-east in the lowest $200 \mathrm{~m}$ compared to northern winds at higher levels (Fig. 4b). The lowest $200 \mathrm{~m}$ were also characterized by strong thermal stratification caused by radiative cooling at the surface, as can be seen in the vertical profile of equivalent potential temperature, $\theta_{e}$ (Fig. 4c). Given that this variable aggregates the effects of moisture, the curve in Fig. $4 \mathrm{c}$ indicates that the surface was colder and drier than the higher levels after the wave passage.

Several meteorological variables were plotted in Fig. 5 in order to further investigate the surface-layer conditions before and after the wave event. The wave occurrence is marked with the thin red vertical bar, when the surface-layer had low wind speeds (panel a), westerly winds (panel b), and decreasing air temperature (panel d). In order to understand what happened in this period, it would be helpful to describe the events marked with thick bars to the right and left (green and yellow). The green bar marks the interval from 1430 to 1630 local time on the same day when the wave was observed. This period was characterized by a strong burst in wind speed (panel a) and a sudden change in wind direction (panel b), a sharp decrease in both equivalent potential temperature, $\theta_{e}$, and air temperature (panels $\mathrm{c}$ and $\mathrm{d}$ ), a rapid increase followed by a decrease in mixing ratio (panel e) and precipitation (panel f). Events with similar characteristics were reported before by Garstang et al. (1998) (and references therein) for the central Amazon region. These disturbances were attributed to strong 


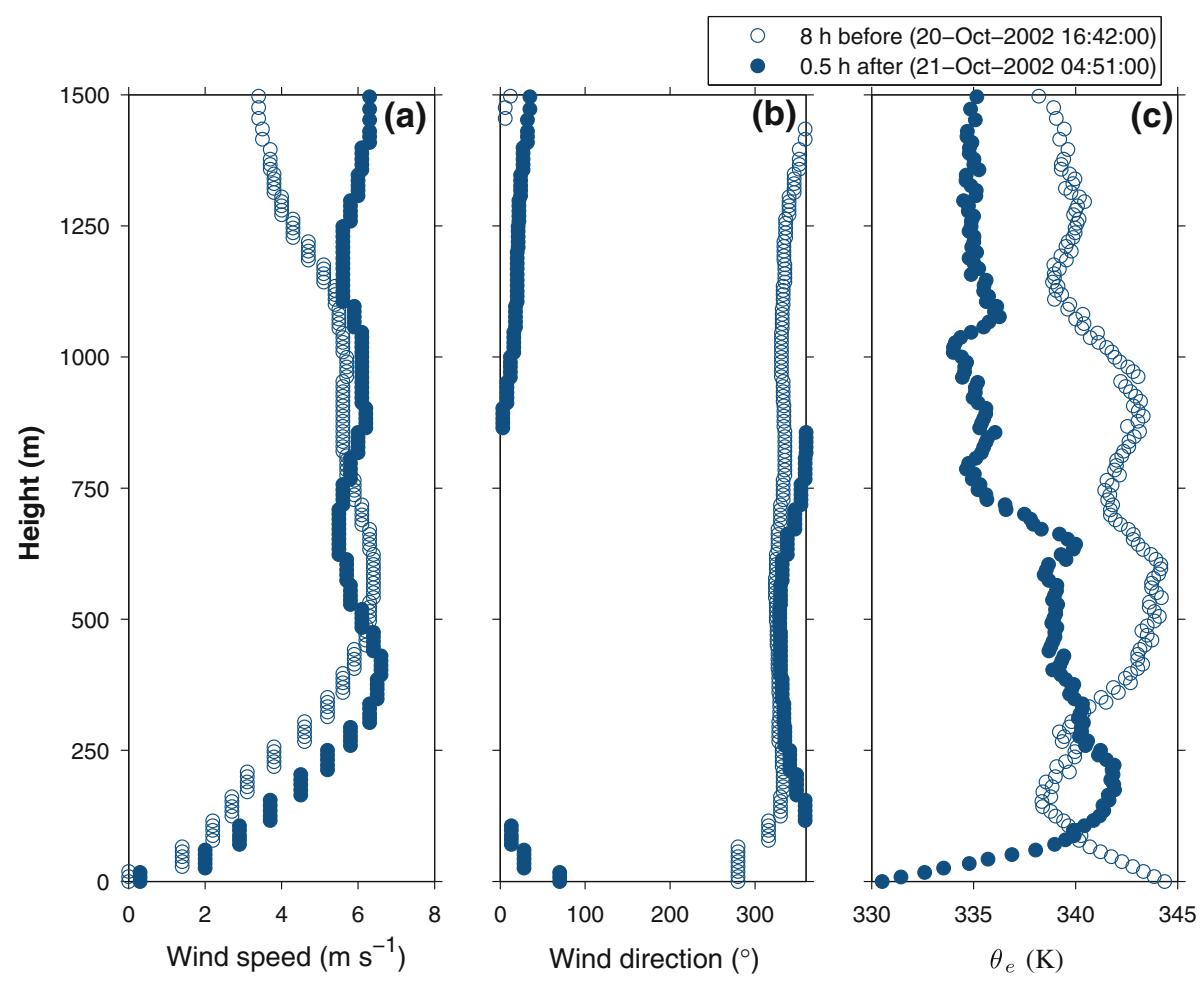

Fig. 4 Rawinsounde data for horizontal wind speed (a), wind direction (b), and equivalent potential temperature, $\theta_{e}(\mathbf{c})$. Open symbols for daytime conditions $8 \mathrm{~h}$ before the event; closed symbols for measurements performed $30 \mathrm{~min}$ after the event

downbursts associated with travelling convective storms. Descending air from clouds above reaches the surface and is converted by inertia into horizontal motion with air spreading over a region of several hectares. This descending motion has different values of air temperature and humidity, causing fast changes in those meteorological variables as it mixes with the air close to the surface. Strong downbursts with similar characteristics were also observed by Nogueira et al. (2006) for the Caxiuanã Amazonian forest site. The mixing caused by these events was associated with up to $50 \%$ of the vertical turbulent transport of heat during nighttime.

The yellow bars after midnight in Fig. 5 mark a period $4 \mathrm{~h}$ before the wave occurrence; this period is referred to as the weak downburst due to its lower impact on the variables. This downburst was associated with the highest wind speeds during the night of the event, while wind direction was the same compared to the daytime event, $\theta_{e}$ fell steadily, air temperature increased and the mixing ratio decreased. The differences compared to the daytime downburst were the increase in air temperature and the absence of rain. The increase in air temperature reveals that this motion brought warmer air to the surface, which is consistent with the vertical profile of air temperature derived from the rawinsounding data (not shown). The decrease in $\theta_{e}$ (panel c) was caused by the decrease in the mixing ratio (panel e), which is used in the calculation of $\theta_{e}$. According to the site picture in Fig. 1, the area surrounding the tower had several bare patches in the forest cover, which could have contributed to the more rapid cooling of the overlaying air and consequent onset of density currents. 


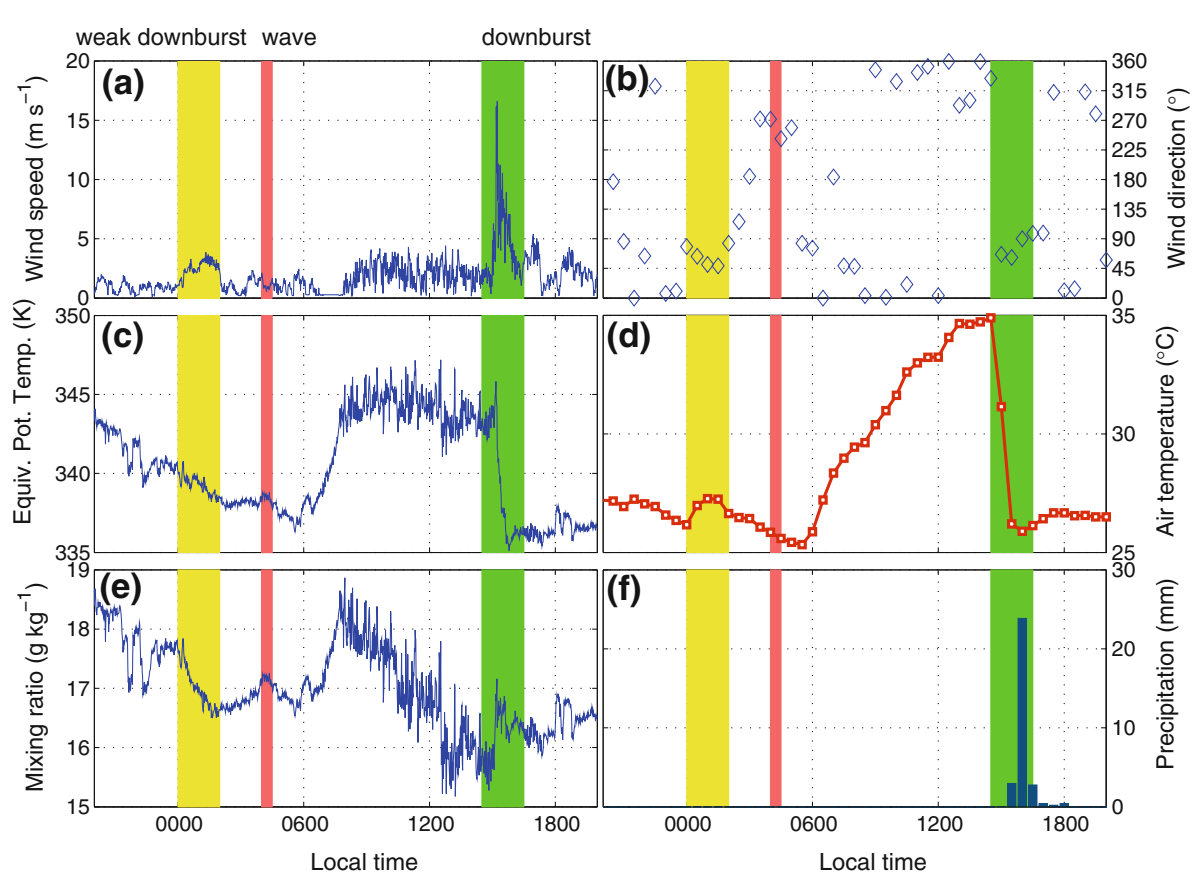

Fig. 5 Meteorological variables for 20-21 October 2002: a wind speed, b wind direction, c equivalent potential temperature, $\mathbf{d}$ air temperature, e mixing ratio, and $\mathbf{f}$ precipitation. Data in left panels are averaged every minute; data in right panels are averaged every $30 \mathrm{~min}$

Simultaneous measurements in multiple towers would be required in order to confirm whether air that occupied the canopy space during the wave occurrence was associated with deforested areas surrounding the tower.

The impact of the wave on the vertical fluxes and other variables can be seen in Fig. 6, where the event occurrence is marked with a vertical arrow on panel a. The concentration of $\mathrm{CO}_{2}$ peaked simultaneously with the wave, implying that the passage of the event mixed the surface-layer, bringing to the flux sensor placed above the canopy the carbon dioxide accumulated below the vegetation during nighttime. The flux of $\mathrm{CO}_{2}\left(F_{C}\right.$, panel b) was negative at the time of the wave, caused by the combination of the turbulence generated by the oscillatory motion and the vertical gradient of $\mathrm{CO}_{2}$. There were no measurements of the vertical profile of $c$ in the 2002 campaign, but from the evolution of $c$ in panel a and the vertical flux in panel $b$ we speculate that the air transported by the wave had a higher concentration of carbon dioxide than the air below the sensor, contributing then to the downward $\mathrm{CO}_{2}$ flux.

The vertical motions induced by turbulence carried $\mathrm{CO}_{2}$-enriched air downwards or $\mathrm{CO}_{2}$ depleted air upwards, resulting in negative fluxes of $\mathrm{CO}_{2}$. Conversely, the sensible heat flux $(H)$ and latent heat flux $(L E)$ (panel b) were positive, indicating that the air moving over the tower was colder and drier than the underlying air. The friction velocity $u_{*}$ (panel d) peaked $2 \mathrm{~h}$ before the event and decreased after that, suggesting low values of the vertical momentum flux. The wave affected not only the measurements above the canopy but also disturbed the vertical profiles of scalars down to the forest floor. The effects of the passage of this event on the vertical profiles of wind, temperature and specific humidity can be seen 


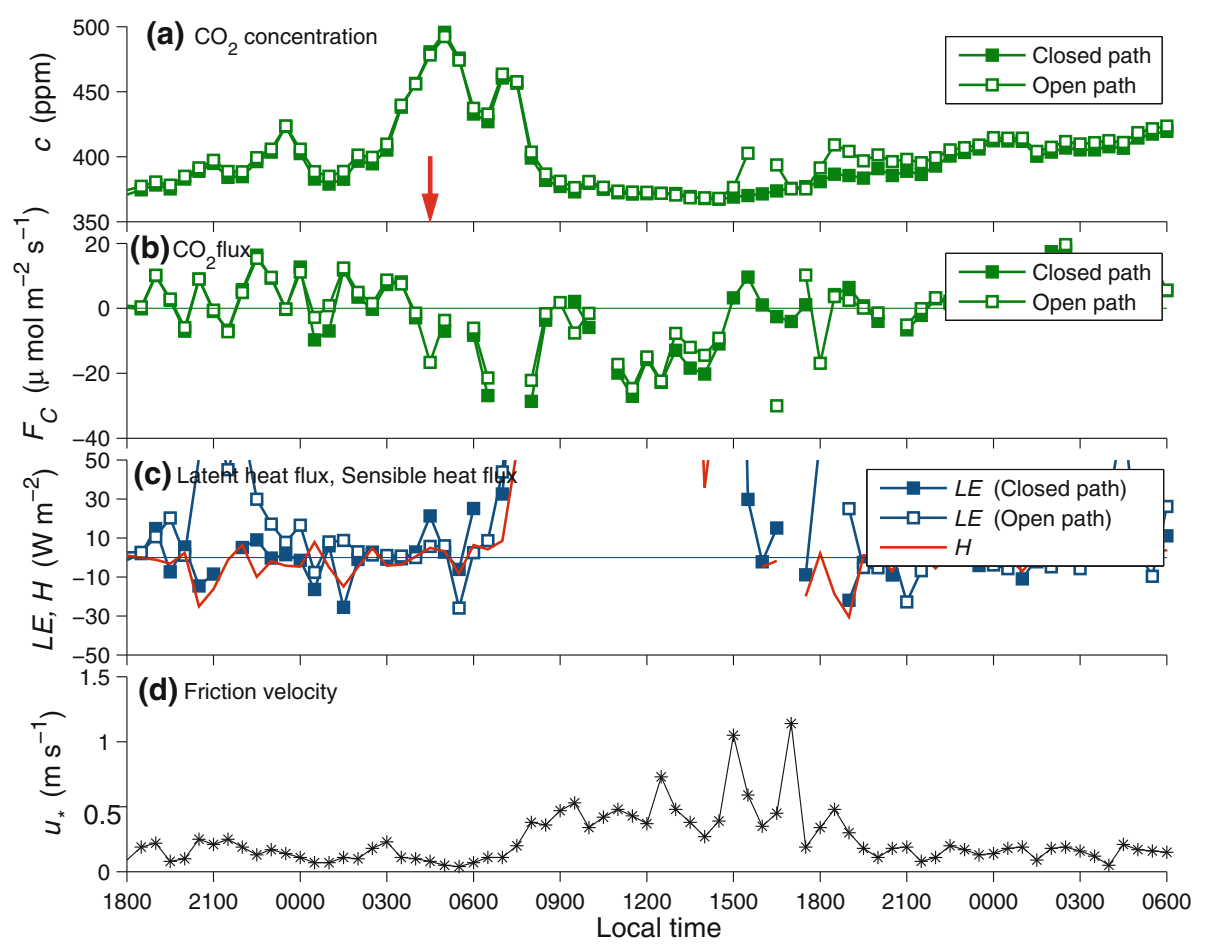

Fig. 6 Time series fluxes and other variables for 21 October 2002. Time of the event marked with the arrow in the topmost panel: a $\mathrm{CO}_{2}$ concentration $(c), \mathbf{b} \mathrm{CO}_{2}$ flux $\left(F_{C}\right)$, c latent and sensible heat fluxes $(H, L E)$ and $\mathbf{d}$ friction velocity $\left(u_{*}\right)$

in Fig. 7. The data in this figure range from $30 \mathrm{~min}$ before to $30 \mathrm{~min}$ after the event, which occurred between 0400 and 0430 local time.

The time-height cross-section of wind speed is shown in Fig. 7a. The highest wind speed above the canopy was observed before (at 0330 and 0400) and after (0430) the wave event. During the wave passage intermediate wind speeds were recorded at $1.7 h$, where $h$ is the canopy height. The influence close to the canopy top $(h \approx 1)$ or lower was intermittent and only related to the strong bursts at higher levels. The cross-section for air temperature in Fig. $7 \mathrm{~b}$ shows that cold air started to fill the canopy space before the wave event and continued steadily during and after the oscillatory motion had passed. The cooling was only affected at 0400 and 0430 , synchronous with the strong bursts of wind that penetrated the canopy upper layer. The evolution of these two variables suggests that intermittent turbulence was associated with the wave evolution and contributed to the vertical exchanges of energy and mass. This result supports the numerical study of $\mathrm{Hu}$ et al. (2002), which proposed the existence of turbulent motions as ejections and sweeps near the canopy top during the passage of a canopy wave.

The air that was moving above and below the vegetation was also drier than the canopy air being displaced, as can be seen in the evolution of the specific humidity in Fig. 7c. The canopy space started to be filled with drier air before the wave event but this process was interrupted by the wind bursts at 0400 and 0430 and continued afterwards. This event is consistent with the schematic view described by Sun et al. (2002) for a gravity current event that 


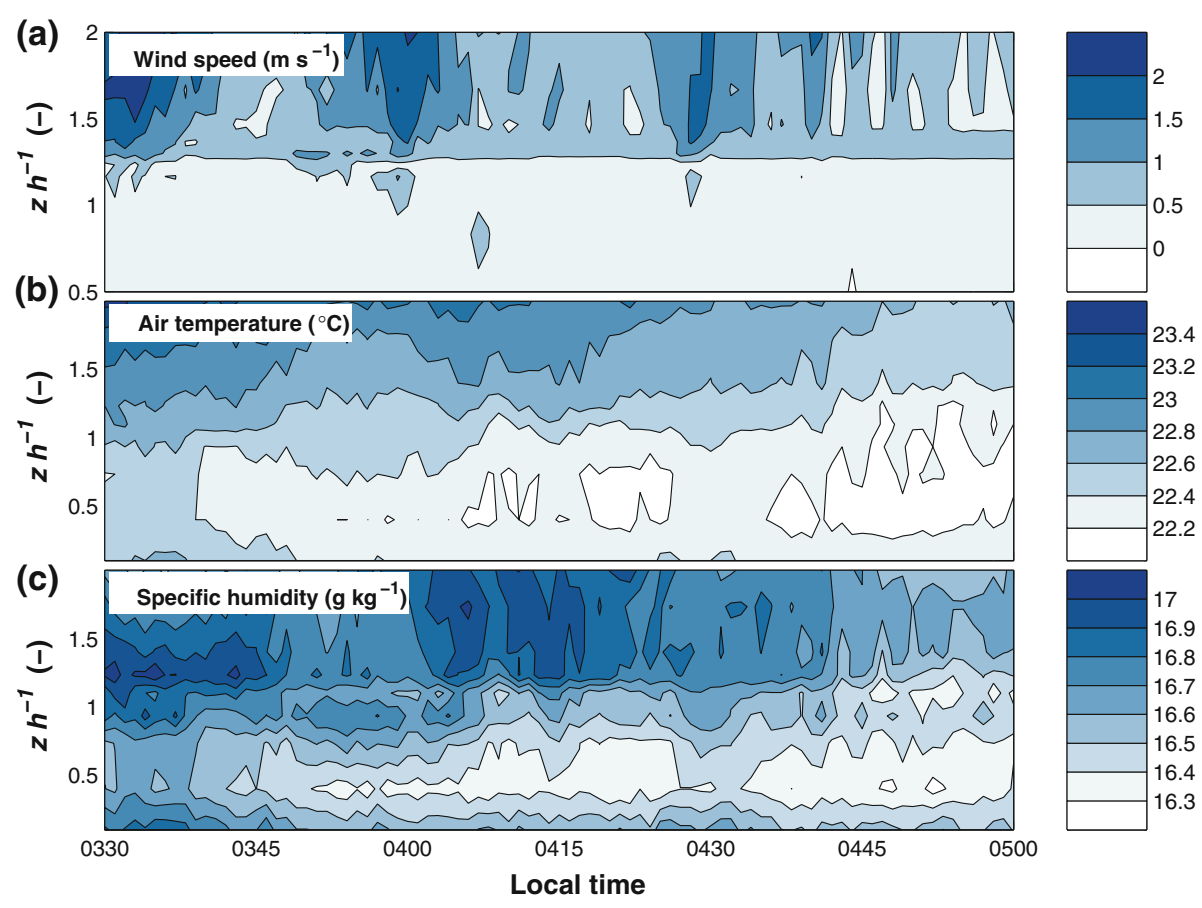

Fig. 7 Cross-section of the wind speed (a), air temperature (b), and specific humidity (c). The wave event happened between 0400 and 0430

moves over the surface carrying mass and energy and initiating turbulent mixing in its path. From the evolution of the cross-section of air temperature and specific humidity presented in this work one can conclude that the gravity wave was associated with a mass of air sweeping the surface and affecting the vertical profiles above and below the canopy. In the next section the high frequency signals of horizontal and vertical velocity, air temperature and $\mathrm{CO}_{2}$ concentration are analysed in order to investigate how this event influenced the vertical and horizontal fluxes of mass and energy.

\subsection{Wavelet Analysis}

Nocturnal fluxes associated with the passage of waves have been observed in other studies (Fitzjarrald and Moore 1990; Lee et al. 1996; Cava et al. 2004). Wave-like motions were observed to contribute to along-gradient or counter-gradient fluxes of $\mathrm{CO}_{2}$ and other scalars depending on the phase relationship between these scalars and vertical velocity (Lee et al. 1997; Cava et al. 2004). In this section, the high frequency data shown in Fig. 3 were analysed in order to investigate the influence of the wave motion on the vertical and horizontal turbulent fluxes. In the previous section it was shown (Fig. 6) that the vertical flux of $\mathrm{CO}_{2}$ was negative and $H$ was positive during the passage of the wave. The processes that led to these fluxes can be understood if one makes use of the cross-wavelet analysis. This technique can be used to decompose the common power between two time series in several time scales, or frequencies. A wave similar to that observed in this study would appear well defined in one frequency band, separated from other phenomena with different time scales, such as 

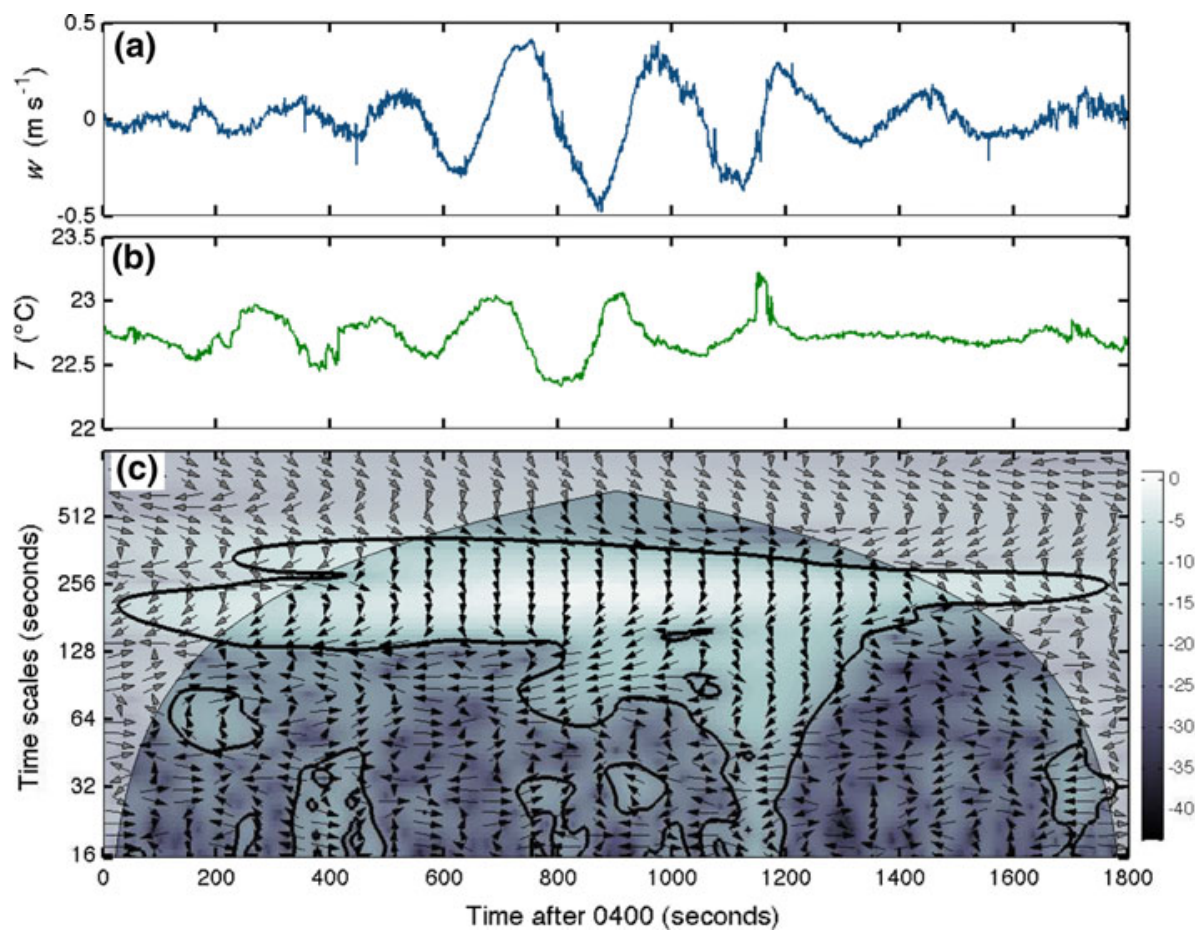

Fig. 8 Time series of vertical velocity (a) and air temperature (b), and periodogram of cross-wavelet power between $w$ and $T$ (c). The colour axis in (c) represents the cross-wavelet power. Arrows angle (trigonometric convention) indicate the phase relationship, thick contour lines enclose regions that are statistically significant, and light shaded regions mark the area where edge effects due to time-series limited size distort the results

turbulence, for instance. From the cross-wavelet output one can also derive the phase relationship between the two signals being analysed. For the specific case of gravity waves the phase between the vertical velocity and temperature, for example, can determine if positive, negative or zero vertical fluxes are associated with the event (Lu et al. 1983). Two time series in phase (phase angle 0) or anti-phase (angle 180) result in positive or negative covariance, respectively. The intermediate value of $\pm 90^{\circ}$ result in zero covariance, or flux, because the peaks and valleys of the wave do not coincide.

The cross-wavelet analysis for vertical velocity and air temperature is shown in Fig. 8. The signals are displayed in panels (a) and (b) and the cross-wavelet power is shown in panel (c). The colour axis is proportional to the common power between the two time series and areas enclosed in black contours are those with a higher significance. The arrows denote the phase relationship between $w$ and $T$ following the trigonometric convention: the arrows pointing right indicate zero phase angle while arrows pointing up or down indicate, respectively, $90^{\circ}$ or $-90^{\circ}$ phase angle (out of phase). That was the case for the relationship between $w$ and $T$ for the period of 180-300 s, the approximate period of the wave. The arrows in that region indicate that the signals had a mean phase angle of $-90^{\circ}$, implying that the wave did not contribute to the turbulent fluxes. However, the mixing caused by the passage of this event resulted in turbulent fluxes at smaller scales (less than $1 \mathrm{~min}$ ) that had in-phase or anti-phase relationships, leading to negative or positive vertical fluxes. This result is in agreement with the small values found for the sensible heat flux in Fig. 6c. A similar relationship was found 

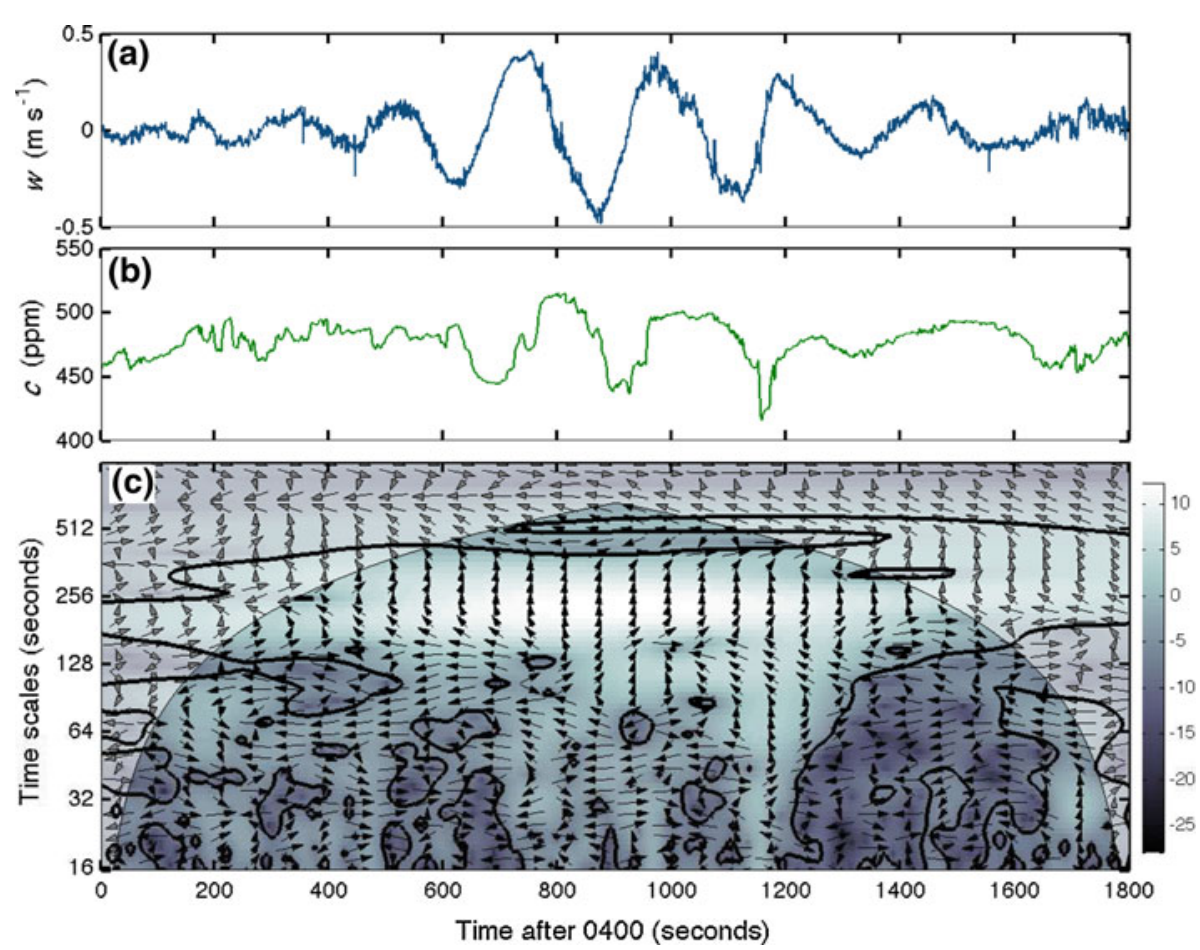

Fig. 9 Same as Fig. 8, for vertical velocity and $c$

for the signals of $w$ and $c$, as shown in Fig. 9. The mean phase angle for these variables for the time scale around $240 \mathrm{~s}$ was of $90^{\circ}$, suggesting no $\mathrm{CO}_{2}$ vertical flux associated with the wave. Similarly to that observed for the sensible heat flux, the turbulent mixing caused by the wave generated large fluxes of $\mathrm{CO}_{2}$ at time scales lower than $1 \mathrm{~min}$.

According to the linear theory of gravity waves, the phase relationship between vertical velocity and scalars is $\pm 90^{\circ}$, depending on the location where measurements are performed (above or within the stand) or on the relationship between the wind speed and phase speed (Lee 1997; Rees et al. 1998, 2001). Lee (1997) modelled the phase relationship between $w$ and $T$ and found it to be approximately $-90^{\circ}$ above the canopy, where a negative value indicates that the maximum in $T$ precedes the maximum in $w$. That was the case for the canopy wave described herein and also for the wave reported by Cava et al. (2004). Although the wave was not related to the vertical fluxes of heat or carbon dioxide, the cross-wavelet analysis between the horizontal velocity component and the signals of temperature and $c$ revealed large horizontal turbulent fluxes. These results are presented in Figs. 10 and 11, for the pairs $[u, c]$ and $[u, T]$, respectively. The horizontal velocity component $u$ was in phase with the temperature signal, resulting in positive turbulent transport of heat in the horizontal. The signals of $u$ and $T$ were also in phase in the canopy waves described in Lee (1997) and Cava et al. (2004). For $u$ and $c$ (Fig. 11) the mean phase angle was $180^{\circ}$ at the scale of 180-300 s, implying negative horizontal turbulent fluxes.

The analysis of the fluctuations induced by the wave on the signals of $T$ and $c$ suggests the occurrence of entrainment of air from higher levels of the nocturnal surface layer. The vertical profile of temperature (Fig. 4) indicates the existence of a temperature inversion, 

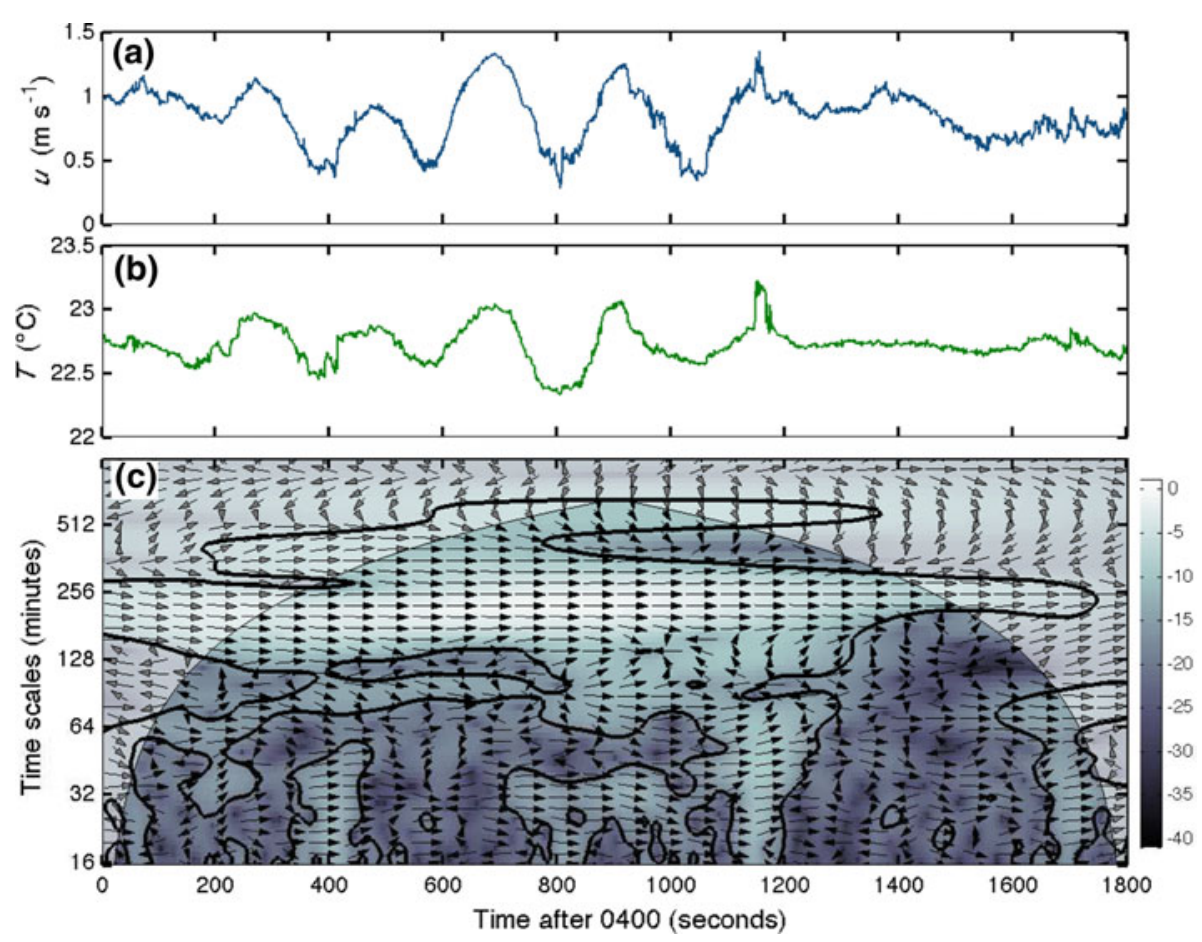

Fig. 10 Same as Fig. 8, for wind speed and air temperature

i.e., the higher the altitude, the warmer the air. Conversely, $c$ is expected to be higher close to the surface given the existence of sources as plant and soil respiration. The departures from the mean for air temperature and $c$ during the passage of the wave were in opposite directions: positive departures in $T$ were associated with negative departures in $c$ and vice versa. This combination suggests that the wave had two alternating stages: a downward motion that carried warmer air from above (lower $c$ ) and an upward motion that carried cool air enriched in carbon dioxide upwards. One would expect the vertical velocity pattern to be consistent with this framework, but the relationship between $w$ and scalars was more complicated given that the changes in $T$ and $c$ preceded the changes in vertical velocity. The determination of the three-dimensional structure of this event would require simultaneous measurements from multiple towers and heights, similar to that done in other experiments that have investigated the stable boundary layer (e.g. CASES-99). It should be noted that the measurements presented herein were made at a height $\approx 2 \mathrm{~h}$, where the horizontal transport might be different from that within the vegetation due to the decoupling of the flows above and below the canopy, which is frequently observed during stable stratification (Knohl et al. 2003; Froelich and Schmid 2006). Indeed, according to the cross-section of the vertical profile of temperature (Fig. 7b), the air below the canopy commenced cooling before the layer above the canopy.

In order to summarise these results, the cross-wavelet coefficients in Figs. 8-11 were summed over $30 \mathrm{~min}$, for each scale, and plotted versus the period, as shown in Fig. 12. The flux associated with each pair of variables is proportional to the area under the curve, similar to the cospectra generated from the traditional Fourier analysis. Areas above the zero line indicate positive fluxes while areas below zero represent negative values. As expected, 

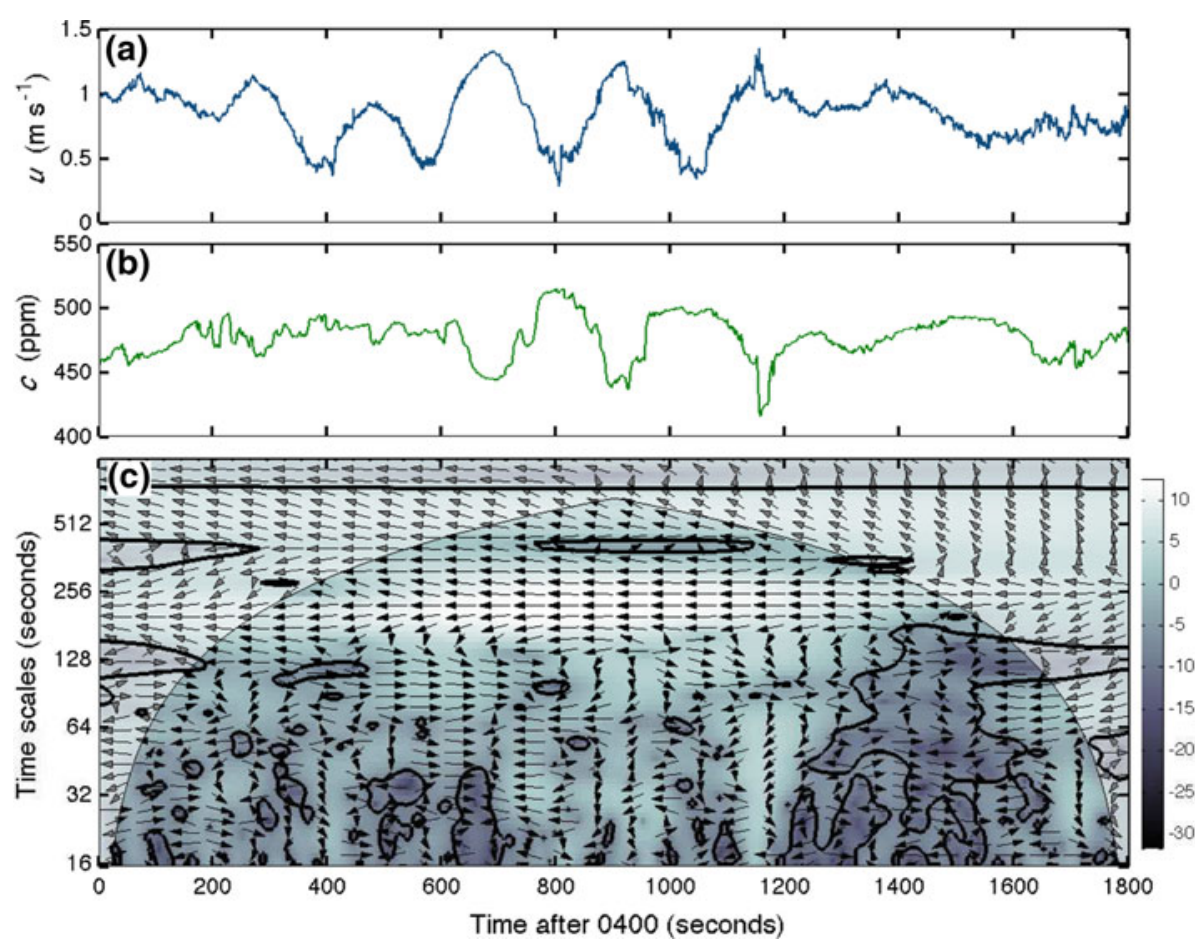

Fig. 11 Same as Fig. 8, for wind speed and $c$

the cospectra for the vertical heat flux and $\mathrm{CO}_{2}$ flux had positive and negative contributions inside the range of the wave period (180-300 s). For $F_{C}$ (panel B), however, negative fluxes also contributed below the time scale of $180 \mathrm{~s}$, which explains the negative flux observed in Fig. 6b. The horizontal fluxes of heat and $\mathrm{CO}_{2}$ were positive and negative, respectively, with no significant contribution from smaller scales.

The passage of the wave had a large impact on the vertical and horizontal fluxes at this site. These results help to describe the complexities associated with nocturnal flows under stable stratification (Lee et al. 1996; Cuxart et al. 2000; Poulos et al. 2002; Sun et al. 2002, 2004). The turbulent and non-turbulent fluxes caused by the wave can be important if one is interested in short-term experiments, in small-scale studies of the vertical profiles above and below the canopy, or in modelling of the vertical exchanges for forest ecosystems. For long-term calculations the impact of such fluxes would be small given that they are associated with strong non-stationarity, i.e., periods when the time series statistic parameters change abruptly over time. When annual balances for carbon or water are calculated, the stationarity is used as a filtering criterion for defining periods of good data quality, which would certainly exclude the data whose periods were associated with waves such as that described in this work. However, if terrain conditions or the site location favour the periodic occurrence of such events, then the inclusion of these fluxes in the annual balances would be recommended as their contribution could be significant for an accurate balance calculation. Measurements at the Jaru forest site during the experiment described herein was screened for other turbulent periods that were associated with negative nighttime fluxes of $\mathrm{CO}_{2}$. However, only one had similar characteristics to the event described here (wave-like pattern on the signals of wind 


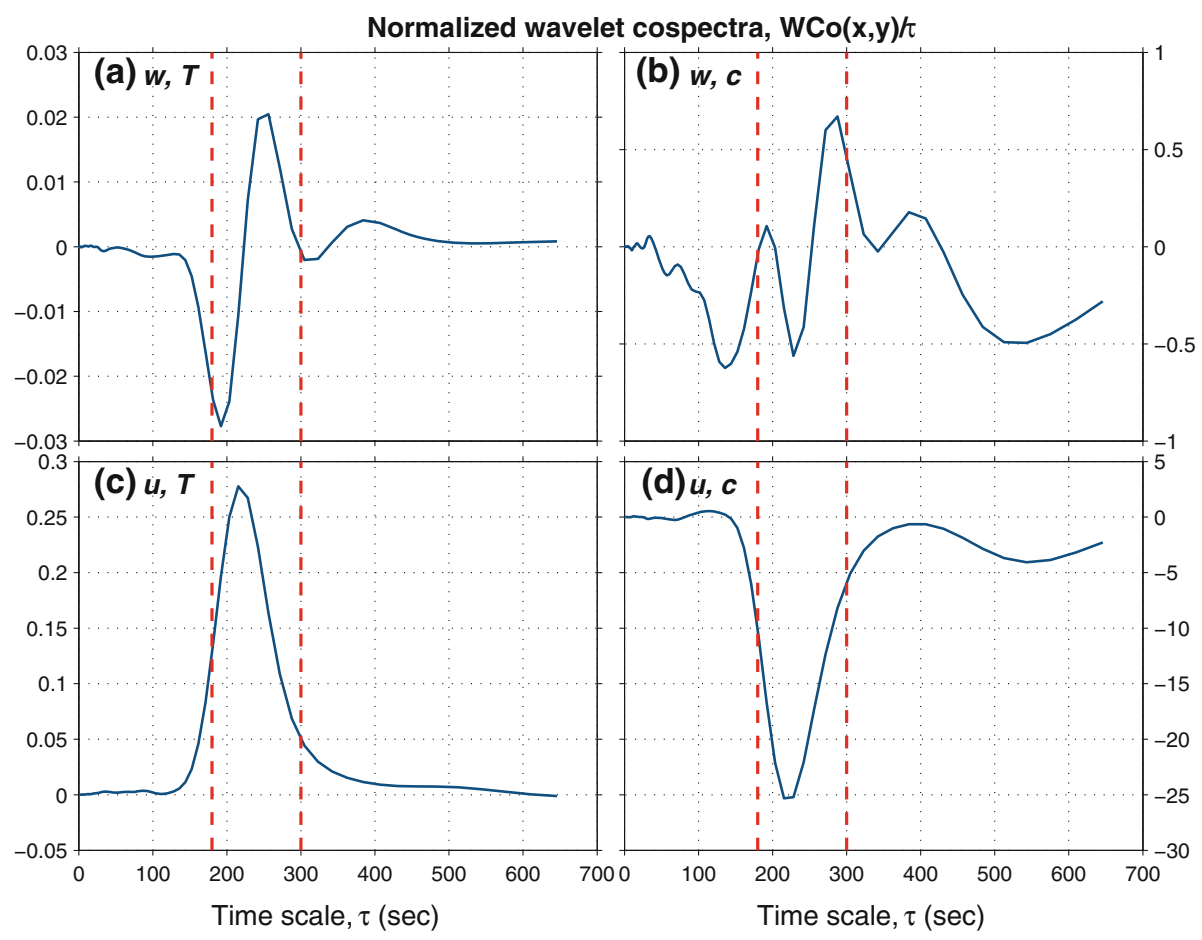

Fig. 12 Wavelet cospectra for $w$ and $T$ (a), $w$ and $c(\mathbf{b}), u$ and $T(\mathbf{c})$, and $u$ and $c$ (d). The vertical lines enclose the approximate period of the wave (180-300 s)

velocity and scalars) and the others contained periods of intermittent turbulence such as those observed by Sun et al. (2004).

\section{Conclusions}

Data collected during an intensive experimental campaign of the LBA project in the southwestern Amazon forest in 2002, during the dry-to-wet transition from September to November, were used to investigate the influence of a gravity wave event on the vertical fluxes estimations performed above the canopy. The wave was recorded on 21 October 2002 between 0400 and 0430 local time and influenced the vertical and horizontal fluxes. The event had a period of 180-300 s and induced strong variability in the time series of vertical velocity and $\mathrm{CO}_{2}$ concentration. Cross-wavelet analysis was used to characterise the phase relationship between the signals of vertical and horizontal velocity and scalars as temperature and $\mathrm{CO}_{2}$ concentration. The signals of $w$ and $T$ were out of phase $\left(-90^{\circ}\right)$, resulting in negligible vertical heat flux $(H)$ associated with the gravity wave. However, the turbulent mixing induced by the oscillatory motion resulted in a small positive value of $H$ in such situations. The signals of $w$ and $c$ were also out of phase $\left(90^{\circ}\right)$, but the turbulence induced by the passage of the wave produced large negative flux. The passage of this event had a large impact on the horizontal turbulent fluxes at this forest site. The signals of the horizontal velocity component and temperature were in phase, resulting in large horizontal fluxes. The phase relationship 
between $u$ and $c$ was $180^{\circ}$, producing a negative horizontal turbulent flux of $\mathrm{CO}_{2}$. This demonstrates that wave-like motions can be responsible for significant turbulent exchanges in the nocturnal surface layer over an Amazon forest site. The similarities between the wave described in our study with those reported elsewhere suggest that oscillatory motions over vegetated surfaces might have universal characteristics that are independent of forest type or structure.

Acknowledgements The authors would like to thank Dr. Gilberto Fisch for kindly providing the rawinsounding data. We are also grateful to all people which directly or indirectly contributed to the realization of the 2002 campaign. Additionally, we would like to thank the support of the University of Rondônia in Ji-Paraná (UNIR), Instituto Brasileiro do Meio Ambiente e dos Recursos Naturais Renováveis (IBAMA) and Instituto Nacional de Colonização e Reforma Agrária (INCRA). This work was done under the framework of the LBA project, financed by the European Union, NASA, and Brazilian Agencies as Conselho Nacional de Pesquisa e Desenvolvimento Tecnológico $(\mathrm{CNPq})$ and Fundação de Amparo à Pesquisa do Estado de São Paulo (FAPESP, process 01/06908-7). Leonardo Sá is particularly grateful to CNPq for his research grant (process 304.981/2007-9), while Marcelo Zeri is grateful to the Energy Biosciences Institute for support during the preparation of this manuscript. We thank Augusto Freire for help with the language.

\section{References}

Andreae MO, Artaxo P, Brandao C, Carswell FE, Ciccioli P, da Costa AL, Culf AD, Esteves JL, Gash JHC, Grace J, Kabat P, Lelieveld J, Malhi Y, Manzi AO, Meixner FX, Nobre AD, Nobre C, Ruivo MDLP, Silva-Dias MA, Stefani P, Valentini R, von Jouanne J, Waterloo MJ (2002) Biogeochemical cycling of carbon, water, energy, trace gases, and aerosols in Amazonia: the LBA-EUSTACH experiments. J Geophys Res Atmos 107(D20):8066

Blumen W, Banta R, Burns SP, Fritts DC, Newsom R, Poulos GS, Sun JL (2001) Turbulence statistics of a Kelvin-Helmholtz billow event observed in the night-time boundary layer during the Cooperative Atmosphere-Surface Exchange Study field program. Dyn Atmos Oceans 34(2-4):189-204

Bolzan MJA, Vieira PC (2006) Wavelet analysis of the wind velocity and temperature variability in the Amazon forest. Braz J Phys 36(4A):1217-1222

Businger JA (1986) Evaluation of the accuracy with which dry deposition can be measured with current micrometeorological techniques. J Clim Appl Meteorol 25(8):1100-1124

Cava D, Giostra U, Siqueira M, Katul G (2004) Organised motion and radiative perturbations in the nocturnal canopy sublayer above an even-aged pine forest. Boundary-Layer Meteorol 112(1):129-157

Chimonas G (1985) Apparent counter-gradient heat fluxes generated by atmospheric waves. Boundary-Layer Meteorol 31(1):1-12

Collineau S, Brunet Y (1993a) Detection of turbulent coherent motions in a forest canopy. 1. Wavelet analysis. Boundary-Layer Meteorol 65(4):357-379

Collineau S, Brunet Y (1993b) Detection of turbulent coherent motions in a forest canopy. 2. Time-scales and conditional averages. Boundary-Layer Meteorol 66(1-2):49-73

Cuxart J, Yagüe C, Morales G, Terradellas E, Orbe J, Calvo J, Fernández A, Soler MR, Infante C, Buenestado P, Espinalt A, Joergensen HE, Rees JM, Vilá J, Redondo JM, Cantalapiedra IR, Conangla L (2000) Stable atmospheric boundary-layer experiment in Spain (SABLES 98): a report. Boundary-Layer Meteorol 96(3):337-370, http://dx.doi.org/10.1023/A:1002609509707

Daubechies I (1992) Ten lectures on wavelets. CBMS-NSF regional conference series in applied mathematics, vol 61. Society for Industrial and Applied Mathematics, Philadelphia, PA, 377 pp

Farge M (1992) Wavelet transforms and their applications to turbulence. Annu Rev Fluid Mech 24:395-457

Finnigan J (1988) Kinetic-energy transfer between internal gravity-waves and turbulence. J Atmos Sci 45(3):486-505

Fisch G, Tota J, Machado LAT, Dias MAFS, Lyra RFD, Nobre CA, Dolman AJ, Gash JHC (2004) The convective boundary layer over pasture and forest in Amazonia. Theor Appl Climatol 78(1-3):47-59

Fitzjarrald DR, Moore KE (1990) Mechanisms of nocturnal exchange between the rain forest and the atmosphere. J Geophys Res 95(D10):16,839-16,850. http://dx.doi.org/10.1029/JD095iD10p16839

Foken T, Goeckede M, Mauder M, Mahrt L, Amiro BD, Munger JW (2004) Post-field data quality control. In: Lee X, Massman WJ, Law B (eds) Handbook of micrometeorology: a guide for surface flux measurement and analysis. Kluwer, Dordrecht, $250 \mathrm{pp}$ 
Froelich NJ, Schmid HP (2006) Flow divergence and density flows above and below a deciduous forest: part II. Below-canopy thermotopographic flows. Agric For Meteorol 138(1-4):29-43

Garratt JR (1990) The internal boundary layer-a review. Boundary-Layer Meteorol 50(1):171-203. http:// dx.doi.org/10.1007/BF00120524

Garratt JR (1992) The atmospheric boundary layer. Cambridge University Press, Cambridge, 316 pp

Garstang M, White S, Shugart HH, Halverson J (1998) Convective cloud downdrafts as the cause of large blowdowns in the Amazon rainforest. Meteorol Atmos Phys 67(1):199-212. http://dx.doi.org/10.1007/ BF01277510

Gash JHC, Nobre CA, Roberts J, Victoria RL (1996) Amazonian deforestation and climate. Wiley, New York, $611 \mathrm{pp}$

Grinsted A, Moore JC, Jevrejeva S (2004) Application of the cross wavelet transform and wavelet coherence to geophysical time series. Nonlinear Process Geophys 11(5-6):561-566

Horst TW, Weil JC (1994) How far is far enough? The fetch requirements for micrometeorological measurement of surface fluxes. J Atmos Ocean Technol 11(4):1018-1025

Hu X, Lee X, Stevens DE, Smith RB (2002) A numerical study of nocturnal wavelike motion in forests. Boundary-Layer Meteorol 102(2):199-223. http://dx.doi.org/10.1023/A:1013167228992

Kaimal JC, Finnigan JJ (1994) Atmospheric boundary layer flows: their structure and measurement. Oxford University Press, New York, 289 pp

Katul G, Vidakovic B (1998) Identification of low-dimensional energy containing flux transporting eddy motion in the atmospheric surface layer using wavelet thresholding methods. J Atmos Sci 55(3):377-389

Knohl A, Schulze ED, Kolle O, Buchmann N (2003) Large carbon uptake by an unmanaged 250-year-old deciduous forest in Central Germany. Agric For Meteorol 118(3-4):151-167

Kruijt B, Malhi Y, Lloyd J, Norbre AD, Miranda AC, Pereira MGP, Culf A, Grace J (2000) Turbulence statistics above and within two Amazon rain forest canopies. Boundary-Layer Meteorol 94(2):297-331

Leclerc MY, Thurtell GW (1990) Footprint prediction of scalar fluxes using a Markovian analysis. BoundaryLayer Meteorol 52(3):247-258. http://dx.doi.org/10.1007/BF00122089

Lee X (1997) Gravity waves in a forest: a linear analysis. J Atmos Sci 54(21):2574-2585

Lee XH, Black TA, denHartog G, Neumann HH, Nesic Z, Olejnik J (1996) Carbon dioxide exchange and nocturnal processes over a mixed deciduous forest. Agric For Meteorol 81(1-2):13-29

Lee X, Neumann HH, DenHartog G, Fuentes JD, Black TA, Mickle RE, Yang PC, Blanken PD (1997) Observation of gravity waves in a boreal forest. Boundary-Layer Meteorol 84(3):383-398

Liu Y, Liang XS, Weisberg RH (2007) Rectification of the bias in the wavelet power spectrum. J Atmos Ocean Technol 24(12): 2093-2102. doi:10.1175/2007JTECHO511.1

Lu CH, Fitzjarrald DR (1994) Seasonal and diurnal-variations of coherent structures over a deciduous forest. Boundary-Layer Meteorol 69(1-2):43-69

Lu NP, Neff WD, Kaimal JC (1983) Wave and turbulence structure in a disturbed nocturnal inversion. Boundary-Layer Meteorol 26(2):141-155

Meillier YP, Frehlich RG, Jones RM, Balsley BB (2008) Modulation of small-scale turbulence by ducted gravity waves in the nocturnal boundary layer. J Atmos Sci 65(4):1414-1427

Moore CJ (1986) Frequency response corrections for eddy correlation systems. Boundary-Layer Meteorol 37(1):17-35. http://dx.doi.org/10.1007/BF00122754

Nogueira DS, Sá LDA, Cohen JCP (2006) Rajadas noturnas e trocas de CO2 acima da floresta de Caxiuanã, PA, durante a estação seca. Rev Bras Meteorol 21(3b):213-223

Poulos GS, Blumen W, Fritts DC, Lundquist JK, Sun J, Burns SP, Nappo C, Banta R, Newsom R, Cuxart J, Terradellas E, Balsley B, Jensen M (2002) CASES-99: a comprehensive investigation of the stable nocturnal boundary layer. Bull Am Meteorol Soc 83(4):555-581

Prabha T, Leclerc M, Karipot A, Hollinger D, Mursch-Radlgruber E (2008) Influence of nocturnal low-level jets on eddy-covariance fluxes over a tall forest canopy. Boundary-Layer Meteorol 126(2):219-236

Rees JM, Anderson PS, King JC (1998) Observations of solitary waves in the stable atmospheric boundary layer. Boundary-Layer Meteorol 86(1):47-61

Rees JM, Staszewski WJ, Winkler JR (2001) Case study of a wave event in the stable atmospheric boundary layer overlying an Antarctic Ice Shelf using the orthogonal wavelet transform. Dyn Atmos Oceans 34(2-4):245-261

Sá LDD, Sambatti SBM, Galvao GP (1998) Applying the Morlet wavelet in a study of variability of the level of Paraguay River at Ladario, MS. Pesqui Agropecu Bras 33:1775-1785

Schotanus P, Nieuwstadt FTM, Debruin HAR (1983) Temperature-measurement with a sonic anemometer and its application to heat and moisture fluxes. Boundary-Layer Meteorol 26(1):81-93

Silva Dias MAF, Rutledge S, Kabat P, Silva Dias PL, Nobre C, Fisch G, Dolman AJ, Zipser E, Garstang M, Manzi AO, Fuentes JD, Rocha HR, Marengo J, Plana-Fattori A, Sa LDA, Alvala RCS, Andreae MO, 
Artaxo P, Gielow R, Gatti L (2002) Cloud and rain processes in a biosphere-atmosphere interaction context in the Amazon region. J Geophys Res Atmos 107(D20):8072

Stull RB (1988) An introduction to boundary layer meteorology. Kluwer, Dordrecht, 666 pp

Sun JL, Burns SP, Lenschow DH, Banta R, Newsom R, Coulter R, Frasier S, Ince T, Nappo C, Cuxart J, Blumen W, Lee X, Hu XZ (2002) Intermittent turbulence associated with a density current passage in the stable boundary layer. Boundary-Layer Meteorol 105(2):199-219

Sun JL, Lenschow DH, Burns SP, Banta RM, Newsom RK, Coulter R, Frasier S, Ince T, Nappo C, Balsley BB, Jensen M, Mahrt L, Miller D, Skelly B (2004) Atmospheric disturbances that generate intermittent turbulence in nocturnal boundary layers. Boundary-Layer Meteorol 110(2):255-279

Terradellas E, Soler MR, Ferreres E, Bravo M (2005) Analysis of oscillations in the stable atmospheric boundary layer using wavelet methods. Boundary-Layer Meteorol 114(3):489-518

Thomas C, Foken T (2005) Detection of long-term coherent exchange over spruce forest using wavelet analysis. Theor Appl Climatol 80(2-4):91-104

Torrence C, Compo GP (1998) A practical guide to wavelet analysis. Bull Am Meteorol Soc 79(1):61-78

Viana S, Yagüe C, Maqueda G (2009) Propagation and effects of a mesoscale gravity wave over a weaklystratified nocturnal boundary layer during the SABLES2006 field campaign. Boundary-Layer Meteorol 133(2):165-188

von Randow C, Sa LDA, Gannabathula PSSD, Manzi AO, Arlino PRA, Kruijt B (2002) Scale variability of atmospheric surface layer fluxes of energy and carbon over a tropical rain forest in southwest Amazonia-1. Diurnal conditions. J Geophys Res-Atmos 107(D20):8062

von Randow C, Manzi AO, Kruijt B, de Oliveira PJ, Zanchi FB, Silva RL, Hodnett MG, Gash JHC, Elbers JA, Waterloo MJ, Cardoso FL, Kabat P (2004) Comparative measurements and seasonal variations in energy and carbon exchange over forest and pasture in South West Amazonia. Theor Appl Climatol 78(1-3):5-26

Webb EK, Pearman GI, Leuning R (1980) Correction of flux measurements for density effects due to heat and water-vapor transfer. Q J Roy Meteorol Soc 106(447):85-100

Zeri M, Sá LDA (2010) The impact of data gaps and quality control filtering on the balances of energy and carbon for a Southwest Amazon forest. Agric For Meteorol 150:1543-1552 